\title{
An empirical comparison of two measures of intertrial organization in free recall
}

\author{
C. RICHARD PUFF AND SANFORD P. HYSON ${ }^{2}$ \\ FRANKLIN AND MARSHALL COLLEGE
}

The extent to which Ss tended to recall a list of words in the same order on successive trials was described by the "subjective organization" and the "intertrial repetition" measures. The descriptions were found to be highly correlated.

A number of recent studies have investigated the tendency of Ss to recall a list of words in the same order on successive trials. Two techniques are being used by different investigators to measure and describe this phenomenon. One of these is Tulving's (1962) subjective organization (SO) measure, and the other is the intertrial repetition (ITR) measure introduced by Bousfield, Puff, \& Cowan (1964).

It has been recognized that the SO and the ITR measures are fundamentally related. They are both positive functions of the extent to which words are repeatedly recalled in the same order. But there are a number of differences between the measures. For example, as derived from information theory, SO represents the observed redundancy in ordering relative to the maximum possible redundancy. The values of SO are thus expressed as proportions. In contrast, the ITR measure is typically expressed as the deviation of observed ITR from the amount expected by chance. As such, the maximum possible amount of ITR varies as a function of the length of the list. These and other differences have generated some suspicion about how much similarity would obtain in the actual description of data.

The purpose of the present study was to assess the extent to which the differences between the measures would result in differences in the description of the intertrial organization phenomenon.

Method

A list of 10 words was drawn from the Connecticut Free Associational Norms of Bousfield et al (1961). The words all began with different first letters, they had zero interitem associative strength according to Deese's (1959) index, and they had only a minimal number of common associative responses. Ten randomized serial orders of the items were prepared, and were presented to each $S$ in a separate randomized sequence.

The Ss were eight male college students and eight female nursing students. They were given instructions to the effect that the same words would appear each time, but that the order of the words would change. The S's task on every trial was to write as many of the words as he could recall, and to write them in any order in which he could remember them.
The items were presented by an automatic slide projector at the rate of one every $2 \mathrm{sec}$ and $30 \mathrm{sec}$ were allowed for recall. Data for 20 trials were obtained for each $\mathrm{S}$.

Results

Values of the SO and the ITR measures were found for each successive pair of trials ( 1 and 2, 2 and 3, etc.) for each $\mathrm{S}$. The values of SO were found by the method described by Tulving (1962). The method for determining the ITR measure followed that described by Bousfield, Puff, \& Cowan (1964), with the exception that the expected amount of ITR was calculated with a formula more recently presented by Bousfield \& Bousfield (1966). The O-E (ITR) deviation score was used in all further analyses unless otherwise noted.

Mean values (across Ss) of both measures were found for each pair of trials, and are shown in Fig. 1. The SO and ITR functions were juxtaposed in the figure by arranging the scales for the two ordinates. The apparent correspondence is supported by a product moment correlation $(\mathrm{r}=.943, \mathrm{~N}=19, \mathrm{p}<.001)$. The same high degree of relationship also held among Ss on each individual pair of trials. The lowest of these 19 coefficients was .903 , and all $p$ values were less than .001 .

In another analysis, SO values were calculated directly for the entire block of 20 trials for each S. These values were then compared to those found by averaging the O-E (ITR) scores for each $S$ across all pairs of trials. The correlation between these two sets of values was .972 $(\mathrm{N}=16)$, which shows that this common way of reporting SO scores does not

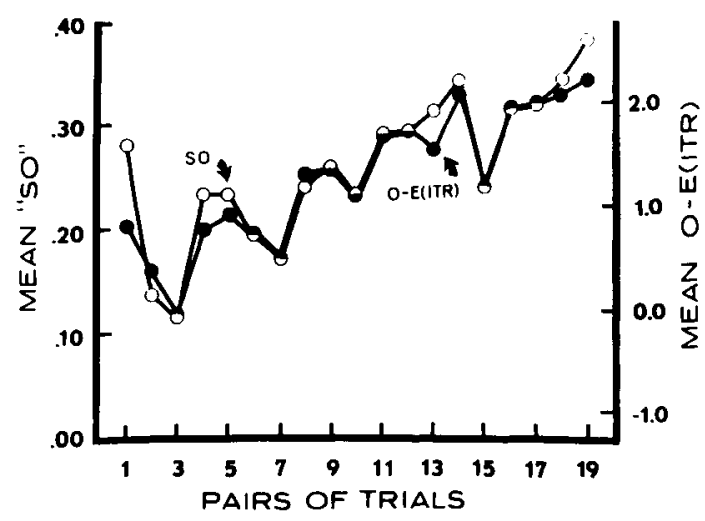

Fig. 1. Mean SO and mean O-E(ITR) as a function of successive pairs of trials. 
attenuate the strength of the relationship between the measures.

The effect of substituting the observed ITR, $O$ (ITR), scores for the O-E (ITR) scores was also investigated. After this substitution, the correlation with SO across trial pairs was only slightly reduced $(r=.917, N=19$, $\mathrm{p}<.001)$.

Finally, data from another experiment were examined. 3 The data of $15 \mathrm{Ss}$ who had received 11 pairs of trials with a list of 17 unrelated words were analyzed in a similar manner. In this case, the correlation between $S O$ and $O-E$ (ITR) across trial pairs was $.980(\mathrm{~N}=10, \mathrm{p}<.001)$.

Conclusions

It is concluded from these results that in spite of some formal differences between the measures, they give highly similar descriptions of the intertrial organization phenomenon. Furthermore, the strength of the relationship seems to be little affected when examined in several slightly different ways. These results would appear to support two general implications:
(1) Efforts to integrate findings from studies using the two measures are justified, and (2) A decision between the measures must be made on some other grounds.

\section{References}

BOUSFIELD, A. K., \& BOUSFIELD, W. A. Measurement of clustering and of sequential constancies in repeated free recall. Psychol Rep., $1966,19,935-942$.

BOUSFIELD, W. A., COHEN, B. H., WHITMARSH, G. A., \& KINCAID, W. D. The Connecticut Free Association Norms. Tech. Rep. No. 35, 1961, University of Connecticut, Contract Nonr-631(00), Office of Naval Research.

BOUSFIELD, W. A., PUFF, C. R., \& COWAN, T. M. The development of constancies in sequential organization during repeated free recall. $J$. verbal Learn. verbal Behav., 1964, 3, 489-495.

DEESE, J. Influence of inter-item associative strength upon immediate free recall. Psychol Rep., 1959, 5, 305-312.

TULVING, E. Subjective organization in free recall of "unrelated" words. Psychol. Rev., 1962, 69, 344354.

\section{Notes}

1. A version of this paper was presented by the senior author at the East. Psychol. Assoc. meetings, Boston, April, 1967.

2. Now at McGill University.

3. These data were kindly provided by Daniel P. Jaffe. 